\title{
El uso de Instagram en la formación del alumnado de arte como complemento a la docencia presencial y a la docencia en red universitaria
}

\author{
María Dolores García González ${ }^{a}$ \\ ${ }^{a}$ Departamento de Escultura, Facultad de Bellas Artes de San Carlos, Universitat Politècnica de València, Camino de \\ Vera, s/n, Edificio 3M - 3N, 46022 Valencia; mail: magargon@upvnet.upv.es
}

\begin{abstract}
This article presents the results of an ongoing study related to the use and potential of the Instagram social network as a complementary tool in the acquisition of skills for the students of the Sculpture II subject in face-to-face and online teaching.

The objective of this research is to present a work proposal that relies on the use of ICT and social networks as possible driving and inspiring elements of artistic practices, especially those oriented to the sculptural field.

For this study, the group f52 Instagram account has been created in order to enhance the learning of the contents of the subject, based on the communicative power that the image has on this platform and its accessibility as well as the possibilities of interaction and generation of multiple content offered.

The project, which is in the Interaction and Redirection phase towards online teaching, was well received by the reference group. The audiovisual materials were seen by $80 \%$ of the members who follow the account that, after the closing of the facilities, it became a virtual space of coexistence for the group.
\end{abstract}

Keywords: Instagram, social networks, teaching, innovation, ITC, fine arts, sculpture, online teaching.

\section{Resumen}

Este articulo expone los resultados de un estudio en curso relacionado con el uso y el potencial de la red social Instagram como herramienta complementaria en la adquisición de competencias para el alumnado de la asignatura de Escultura II en la docencia presencial y en red.

El objetivo de esta investigación es el de presentar una propuesta de trabajo que se apoye en el uso de las TIC y redes sociales como posibles elementos propulsores e inspiradores de las prácticas artísticas, especialmente aquellas orientadas al ámbito escultórico.

Para dicho estudio se ha creado la cuenta grupo f52 de Instagram con el fin de potenciar el aprendizaje de los contenidos de la asignatura, tomando como base el poder comunicativo que tiene la imagen en esta plataforma y su accesibilidad así como las posibilidades de interacción y generación de múltiples contenidos que ofrece.

El proyecto, que se encuentra en la fase de Interacción y Redireccionamiento hacia la docencia en linea, fue bien acogido por el grupo de referencia.. Los materiales audiovisuales fureron vistos por el $80 \%$ de los miembros que siguen la cuenta que, tras el cierre de las instalaciones, pasó a ser un espacio virtual de convivencia para el grupo.

Palabras clave: Instagram, redes sociales, innovación docente, TIC, bellas artes, escultura docencia en red. 


\section{Introducción}

Como afirma Lazo (2018), vivimos en un mundo interconectado con unas posibilidades de comunicación inimaginables hasta hace solo unas décadas, por lo que resulta imprescindible preguntarse sobre nuevas maneras de enseñar y aprender (Aparici 2010). Por este motivo no debemos perder las posibilidades de aprendizaje y refuerzo que redes sociales y las nuevas aplicaciones informáticas (APP) ofrecen a los sistemas educativos formales.

Según el Estudio Anual de Redes sociales (2020) la intensidad de uso de las redes durante este año ha aumentado respecto al anterior pasando de $55 \mathrm{~min}$ (en promedio) a $1 \mathrm{~h} 20 \mathrm{~min}$ y dado que, el $48 \%$ de los usuarios son universitarios, la orientación docente de las redes sociales puede ser muy positiva para la enseñanza universitaria.

Este artículo expone las diferentes fases de desarrollo y los resultados de un estudio en curso relacionado con el uso de la red social Instagram como herramienta complementaria en la adquisición de los contenidos y competencias de la asignatura de Escultura II para segundo curso del Grado en Bellas Artes de la facultad de Bellas Artes de San Carlos (Universitat Politècnica de València).

El proyecto que se enfoca para el Grupo $\mathrm{F}$ de dicha asignatura durante el segundo semestre del curso 2019-2020 se inicia con la creación de la cuenta grupo_f52 en Instagram. Superadas las fases iniciales de Creación y Adaptación, el estudio se encuentra en la Fase de Interacción y Redireccionamiento de la red social hacia la docencia en línea. La propuesta que, desde un principio fue bien acogida por los alumnos, se convirtió tras el cierre de las instalaciones y talleres de escultura, en un espacio virtual de convivencia para gran parte del grupo.

\section{1. ¿Por qué Instagram?}

El creciente desarrollo de las Tecnologías de la Información y la Comunicación (TIC) han conformado, durante los últimos años, nuevos escenarios virtuales donde relacionarse (Gabelas, Marta-Lazo \& Aranda 2012), e Instagram es un claro ejemplo de ello ya que se trata de la segunda red utilizada en el panorama español por encima incluso de Facebook como queda reflejado en el Estudio Anual de Redes sociales (2020) (Fig. 1).

\section{Uso de redes | Frecuencia}

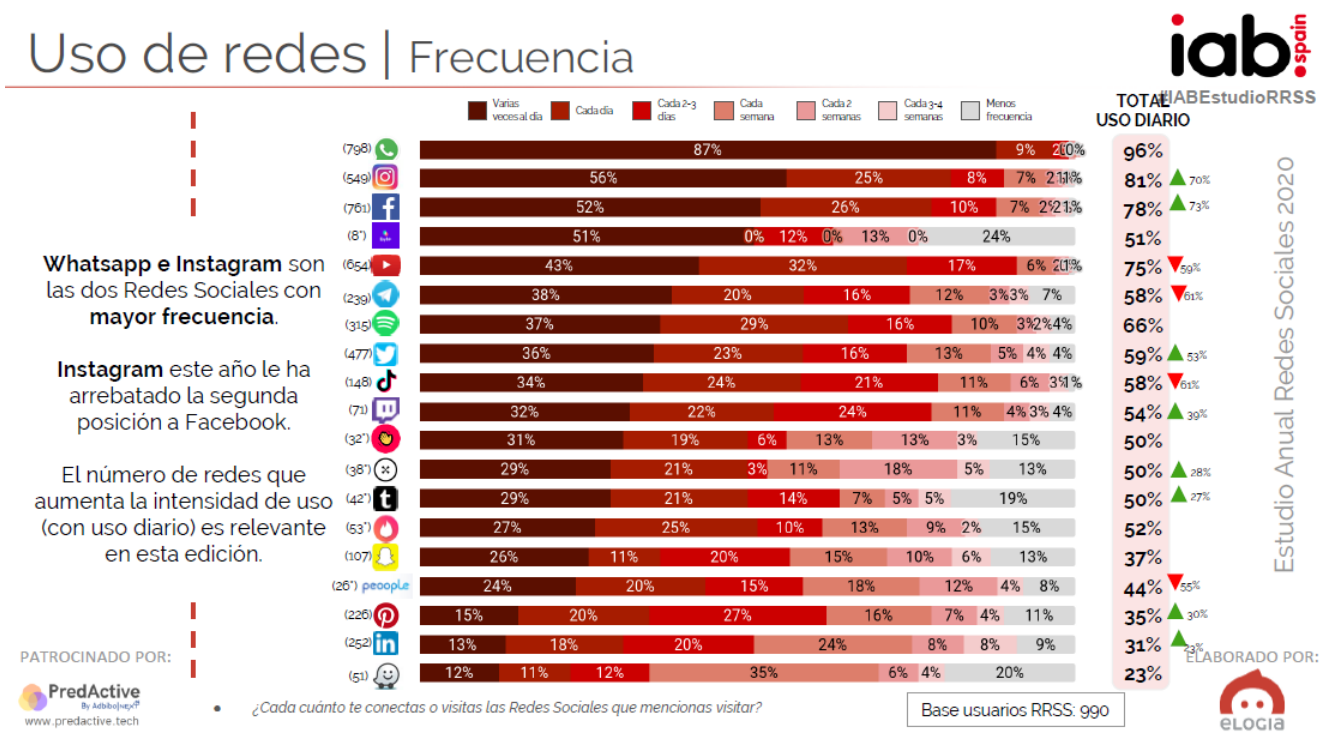

Fig. 1 Uso de las principales Redes Sociales por la población española en el 2020 
Además, mientras que otras plataformas son genéricas, Instagram se basa en la captura de instantáneas como soporte de la información. Su uso intuitivo, así como la facilidad con la que se puede interactuar con el contenido que almacena lo convierte en una plataforma muy atractiva para los artistas y una herramienta muy interesante para el docente en un aula de arte. Las escuelas de márquetin lo usan como galería virtual y muchos ilustradores, artistas callejeros o escultores han sabido adaptar y sacar provecho de la plataforma de Instagram al usarla como medio de promoción para sus obras.

El Informe Hixcox del mercado del arte online (2019) confirma un crecimiento del 9,8\% del mercado de arte online en 2018. El 41\% de las plataformas online cree que el mercado seguirá creciendo vinculado a plataformas especializadas en un tipo de arte o formato determinado. Otra de las conclusiones del informe es que Instagram consolida su liderazgo: el $65 \%$ de los consumidores elige Instagram como su red social preferida para fines relacionados con el arte. Confirmando que el $29 \%$ de los compradores de esta generación adquieren arte online, o que el $23 \%$ de ellos afirma no haber comprado nunca arte en un espacio físico como galerías, subastas o ferias de arte.

La proyección laboral que el uso de esta APP puede suponer para el estudiante durante su periodo de formación permite en palabras de Lazo (2018) que el acercamiento de la educación y la comunicación se vea estimulado por la reapropiación de los conocimientos, reflexionando sobre las interpretaciones de modo relacional, poniendo énfasis en el proceso y centrándose en la persona.

Pero no solo eso, Instagram es una Red Social optimizada para dispositivos móviles y, en España, el móvil lidera la conexión a las Redes Sociales siendo el principal dispositivo para conectarse a ellas (97\%). Además, según el Informe Aprendizaje Móvil para Docentes elaborado por la UNESCO (2012), los teléfonos móviles «son comunes incluso en áreas donde las computadoras y las instituciones de formación docente son escasas» (p. 8). De hecho, podemos hablar de usuarios intensivos (Ramos, Herrera y Ramírez, 2009) que no sólo cuentan con este tipo de dispositivo, sino que lo utiliza constantemente.

El alto grado de penetración de los dispositivos móviles en España facilitan la movilidad del conocimiento, accesible en cualquier momento y en cualquier lugar. Esta realidad facilita al usuario el acceso a la Red Social, aunque carezca de otros soportes tecnológicos disminuyendo la posible brecha digital entre los miembros del grupo de referencia.

El Informe desarrollado por ISEA (2009) afirma que, aunque la integración de la tecnología móvil en los procesos de enseñanza y aprendizaje es una realidad en las aulas y puede aportar múltiples ventajas tanto a nivel funcional como pedagógico, los dispositivos móviles no son útiles como herramientas educativas por sí mismos por lo que, si abandonamos el encauzar su potencial (Semana del Aprendizaje Móvil organizada por la UNESCO 2011) desatendiendo el nuevo ecosistema imperante, estamos dejando que este pueda volverse en contra de los sistemas actuales de aprendizaje.

\section{Objetivos}

El currículo de la asignatura pretende contribuir al desarrollo del pensamiento crítico del alumno, dotándole de un bagaje técnico y artístico que le permita leer y relacionar distintas manifestaciones culturales, históricas o científicas y acontecimientos contemporáneos, para generar estrategias y discursos que contribuyan al desarrollo de propuestas creativas a nivel formal y conceptual.

Esta investigación tiene como Objetivo General presentar una propuesta de trabajo que se apoye en el uso de las TIC y redes sociales como posibles elementos propulsores e inspiradores de las prácticas artísticas, especialmente aquellas orientadas al ámbito escultórico dentro de la docencia universitaria. 
Agrupamos en cuatro los Objetivos Específicos dentro del ámbito de la asignatura de Escultura II:

En primer lugar, contribuir mediante la incorporación del uso de Instagram a un cambio del papel del estudiante como sujeto pasivo dentro del aula, aumentando su interés por la asignatura. Desarrollando el abanico de posibilidades plásticas de la signatura con el fin de acercarse a un estudiante de perfil no específicamente escultórico.

En segundo lugar, trabajar elementos trasversales como el desarrollo de las competencias digitales, la comunicación o el emprendimiento. Iniciando al alumno en el ámbito de las redes profesionales relacionando al mismo tiempo los contenidos de la asignatura con prácticas profesionales en activo fuera del aula.

En tercer lugar, potenciar el valor de la imagen como elemento representativo y narrativo de nuestra obra, generando un archivo visual del curso y de la asignatura, haciendo hincapié en los procesos e incorporando historias y artistas que sirvan de referencia para los alumnos.

Por último, trabajar y potenciar la colaboración e interacción grupal a través de las redes sociales, generar un lugar de encuentro e interacción para todos los alumnos del curso favoreciendo una mirada crítica y analítica del hecho artístico apoyada por el análisis colectivo.

\section{Desarrollo de la innovación}

El uso de la red social Instagram como plataforma docente se propone al inicio del segundo semestre del curso 2019-2020 en la asignatura de Escultura II del Grado en Bellas Artes de la facultad de Bellas Artes de San Carlos (Universitat Politècnica de València) tras comprobar que las características del grupo de referencia facilitaban la incorporación de esta red social a la dinámica de las clases. Esto refuerza el estudio de González, Lleixà y Espuny (2016), que afirma que por un lado, las redes sociales siguen avanzando en su uso social y por otro, no se observan grandes reservas en el alumnado acerca de incorporarlas en la vida universitaria con normalidad.

La asignatura de Escultura II, que toma de referencia la escultura del siglo XX y la escultura contemporánea, es troncal (15 ECTS) y, por lo tanto, de carácter obligatorio para los alumnos de segundo. En el presente curso (2019/2020) cuenta con unos 334 alumnos matriculados, repartidos en 7 grupos (del A al G), siendo 9 los docentes que componen su profesorado. El trabajo del alumno consta de 150 horas para trabajo presencial en los talleres. Las prácticas escultóricas de referencia en el currículum de la asignatura abarcan métodos aditivos, sustractivos y constructivos, recogiendo también el vaciado y las nuevas tecnologías asociadas a la instalación.

Para cubrir este extenso programa la asignatura cuenta con un aula teórica, dos espacios adaptados para el trabajo de los alumnos, acceso a los talleres de madera y metal de la facultad y una sala para el préstamo de herramienta. Estos espacios compartidos, la necesidad de coordinación y convivencia para el préstamo de la herramienta y la ayuda requerida por muchos de los procesos asociados al temario, ya sea por parte del profesor como por parte de los compañeros del aula, le otrogan a la asignatura un fuerte componente colaborativo que comparte según Martín-Moreno (2004), con las redes sociales facilitanto la interacción entre ambas realidades.

Muchas de las técnicas necesarias para el desarrollo de las diferentes propuestas pedagógicas no son frecuentes fuera de las aulas universitarias por lo que la mayoría de los estudiantes muestran recelo a la hora de iniciarse en su práctica. El archivo visual generado por la red social parte con la premisa de poner en valor dichos procesos, empoderando al alumno que ve como su trabajo tiene visibilidad y repercusión 
en las redes, al mismo tiempo que el resto de estudiantes se familiariza con las posibilidades técnicas del aula.

Esta reciprocidad existente en el aula es aumentada por las redes sociales que, en palabras de MartínMoreno (2004), acrecientan la motivación por aprender; favorecen un mayor rendimiento académico, dado que se produce una retroalimentación entre el aprendizaje individual y grupal; mejoran la retención de lo aprendido; potencian el pensamiento crítico; y, multiplican la diversidad de conocimientos y de experiencias adquiridas. Y, de igual modo, hacen que el aprendizaje sea más interactivo y significativo (Imbernón, Silva y Guzmán, 2011).

Debemos apuntar que el uso principal que los jóvenes hacen de la tecnología se centra en reforzar su ámbito comunicativo más cercano (Martín-Moreno 2004), como consecuencia es necesario desmitificar la idea de que nuestros jóvenes están sobradamente preparados para «un mundo» digital, reconociendo que es en «su mundo» digital donde se desenvuelven perfectamente y necesitan que los procesos educativos les ofrezcan medios, procesos y entornos donde alcancen un desarrollo basado en capacidades más amplias que las meramente comunicativas (De La Torre, 2009).

Respondiendo a esto, la innovación se divide en cinco fases que pretenden facilitar el uso y la implantación de la red Social Instagram en el grupo de estudio como fase previa a su posterior incorporación como herramienta docente por parte de la asigantura. La Fig.2 muestra la secuencia de las fases en las que se ha dividido la innovación, encontrándonos actualmente en la Fase 3 donde la respuesta del alumnado toma vital importancia.

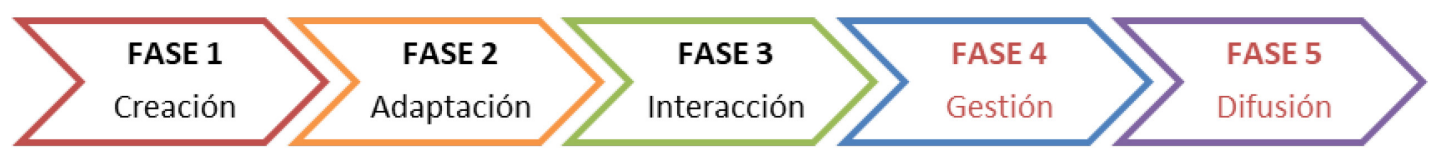

Fig.2. Secuencia de la implantación de las fases de la innovación

\subsection{Fase de Creación}

Teniendo en cuenta lo anterior, el objetivo inicial de esta fase se centra en crear una cuenta para el grupo de clase dentro de la plataforma Instagram a modo de galería para hacer visibles las propuestas desarrolladas por los estudiantes.

Tras contar con luz verde para la iniciativa por parte del equipo docente de Escultura II se procede a debatir la creación y normas de una cuenta de Instagram con el grupo de referencia seleccionado (F) mediante consulta directa.

Este grupo carece de un perfil artístico definido y solo el $16 \%$ de la clase se inclina hacia la vertiente escultórica que anuncia la asignatura. Dadas las posibilidades plásticas que añade esta propuesta a los contenidos del curso la iniciativa tiene muy buena acogida por parte de todo el colectivo.

El grupo de estudio esta constituido inicialmente por 52 alumnos, de ahí el nombre que recibe la cuenta creada: grupo_f52. En la Fig.3 vemos los diferentes logos que se barajaron como imagen de la cuenta. Finalmente fue elegido el diseño recogido por la imagen de la derecha. utilizando el logo de Escultura II como la imagen de perfil. 

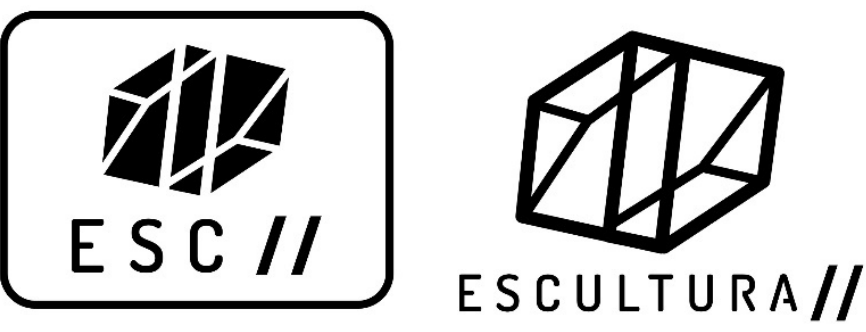

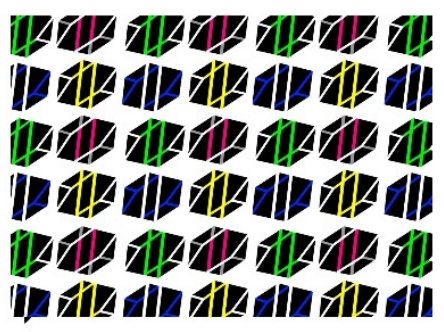

Fig. 3. Logos para la asignatura de Escultura II diseñados por Álvaro Terrones Reigada.

La Fase 1 coincide con la entrega del ejercicio realizado para la UD2: Escultura y Objeto, por lo que se orienta a registrar fotográficamente las presentaciones de los trabajos escultóricos en el Espacio expositivo multidisciplinar T4 reservado para ello, con la intención de publicar posteriormente el material generado.

En esta fase, el contenido de la cuenta es gestionado por la docente responsable del Grupo F, mientras que las fotos las realizada una alumna designada con anterioridad al día de la exposición. Dicha elección sigue los criterios de una adaptación curricular no significativa.

\subsection{Fase de Adaptación}

Las diferentes mejoras adaptativas que sufre el proyecto están estrechamente relacionadas con la observación directa y el análisis del material generado por parte del alumno a lo largo de las propuestas pertenecientes a las tres Unidades Didácticas en las que se desglosa la asignatrua ${ }^{1}$ con las que convive: Escultura y Objeto, Escultura y Naturaleza y Escultura y Espacio, por lo que la adapatación es continua.

Tras la puesta en marcha de la Fase 1, se detectan varias problemáticas: por un lado, se pierde la espontaneidad y las posibilidades de interacción que ofrece la red durante el desarrollo de los ejercicios, por otro, las fotografías realizadas no cuentan con un registro profesional que ponga el valor el trabajo de los alumnos.

Para solventar estas dificultades se opta en primer lugar por incluir un registro fotográfico de las sesiones presenciales y así hacer visibles los procesos constructivos de los proyectos de cada alumno. Fue así como la cuenta comienza a ser un archivo visual colectivo de los diferentes procesos y técnicas escultóricas que se trabajan dentro de los talleres habilitados para la asignatura.

En segundo lugar se pone en valor la toma fotográfica durante las sesiones presenciales para indicar a cada alumno cómo mejorar la narración de sus procesos creativos con la intención de que ellos mismos generen material visual de calidad. Se utiliza para ello una selección de trabajos fotografiados que se suben a modo de ejemplo dentro de la plataforma. La Fig.4 muestra una imagen de la cuenta creada con una primera selección de trabajos para el bloque de Escultura y Naturaleza.

\footnotetext{
${ }^{1}$ La asignatura de Escultura II se divide en cuatro UUDD: Escultura y Cuerpo, Escultura y Objeto, Escultura y Naturaleza y Escultura y Espacio, pero solo conincide con tres de ellas. .
} 


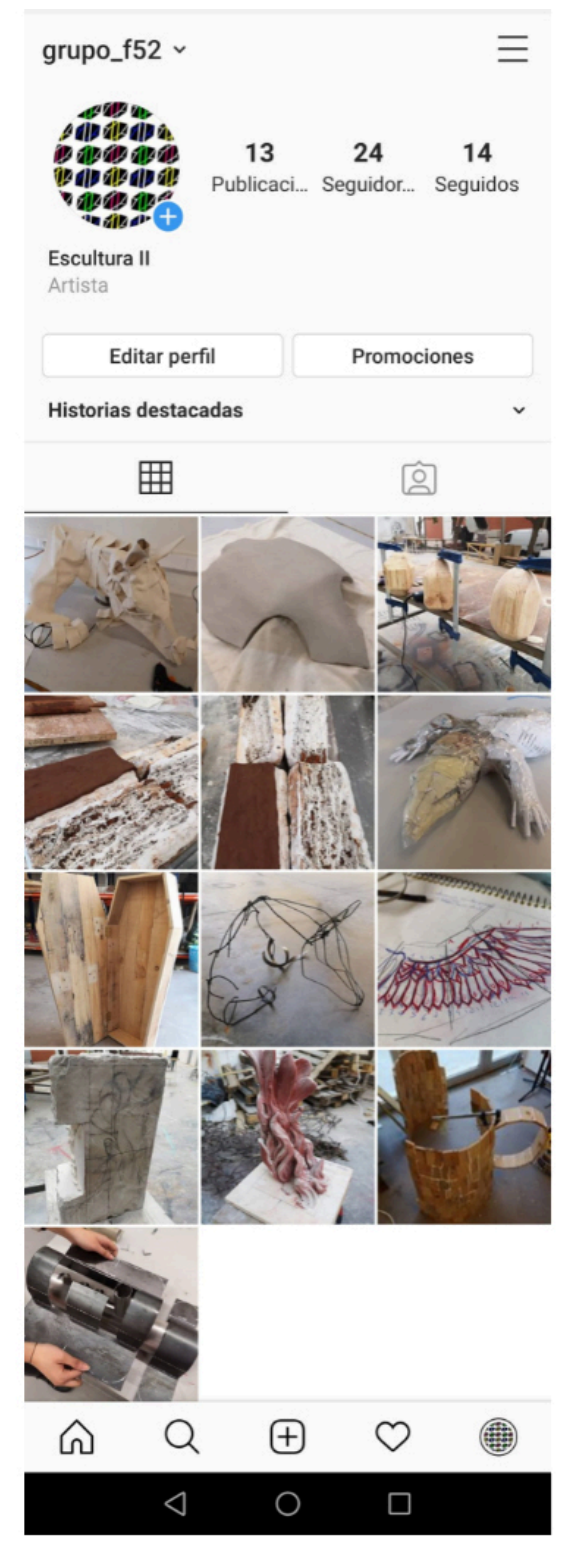

Fig.4. Fotografias subidas a la cuenta grupo f52. Las imágenes seleccionadas hacen visibles procesos escultóricos relacionados con la asignatura

El alumno desarrolla un trabajo de campo, recogiendo, documentando y fijando ideas, referentes, imágenes y reflexiones, dentro y fuera del aula que se presenta como memoria al final de cada bloque y que tiene un peso de $20 \%$ sobre la nota final del ejercicio, la mejora en las imágenes supone una mejor valoración de la misma.

\subsection{Fase de Interacción y docencia no presencial}

Otra de las problemáticas a la que se enfrentan los alumnos parte del hecho de que la asignatura de Escultura II es una de las primeras en incorporar a sus competencias la síntesis de propuestas a través del pensamiento crítico para generar aportaciones creativas propias, por lo que muchos estudiantes muestran una gran dificultad a la hora de desarrollar conceptualmente dichas aportaciones. 
A través de facilitar los perfiles de artistas, galerías y asociaciones de interés en Instagram se facilita a los estudiantes el que puedan acceder a una información relevante y actual de manera fácil y directa (Fig. 5), del mismo modo que, al pedir a los alumnos que compartan con la cuenta de clase aquellos artistas que siguen a título personal, se involucran en la generación de contenido facilitando la interacción de todo el grupo con la red.

Este incentivo responde a que no debemos partir de la idea de que nuestros menores disponen de una destreza natural para moverse en los nuevos entornos tecnológicos. Se necesitan pequeñas ideas prácticas y buenos referentes metodológicos que nos permitan abrir el limitado mundo que se desarrolla de forma digital en torno a nuestros jóvenes (De La Torre, 2009).
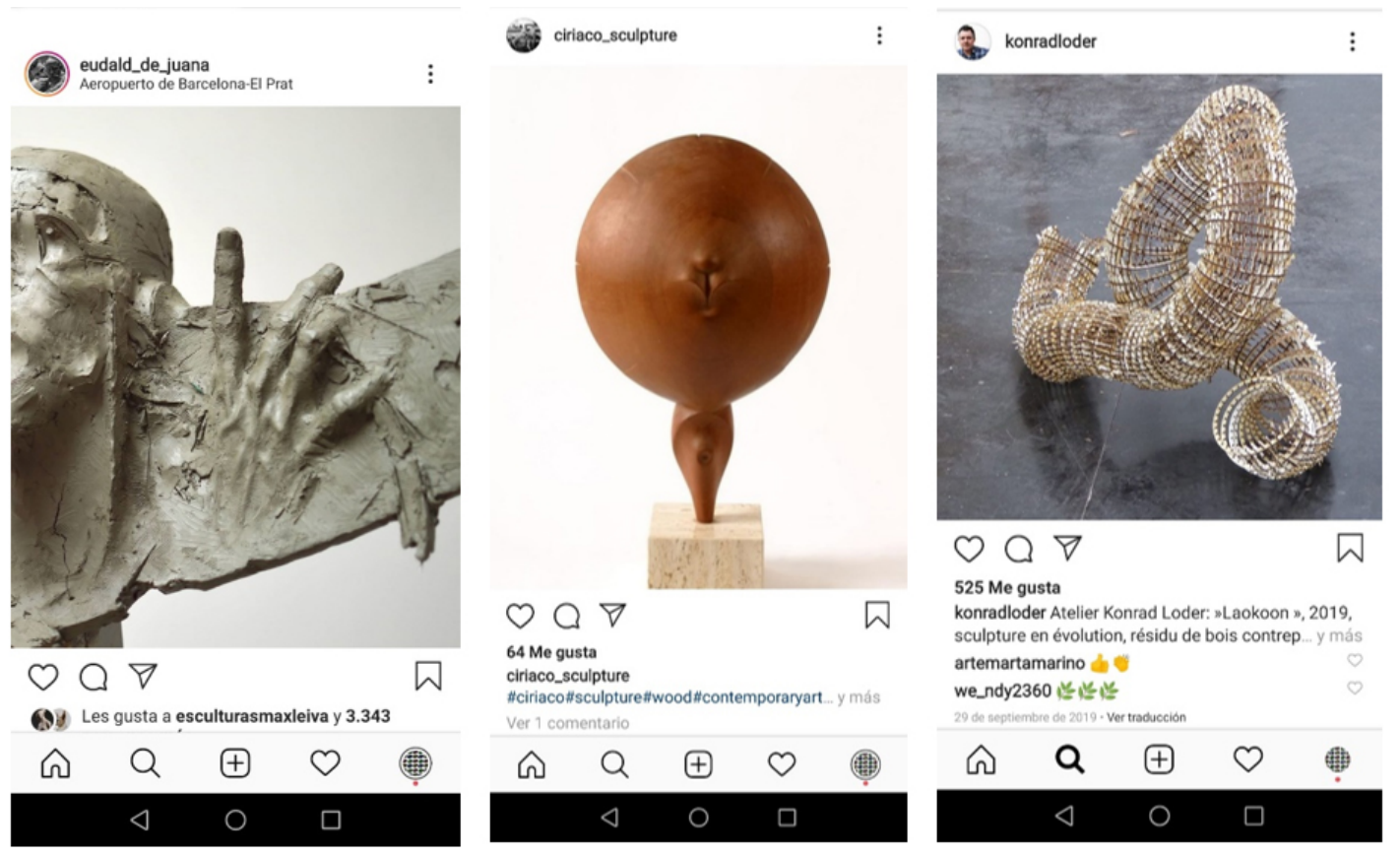

Fig. 5. Ejemplos de artistas seguidos por la cuenta del grupo_f52 que ponen de manifiesto las capacidades plásticas de la escultura contemporánea .

\subsubsection{Docencia no presencial}

Con el paso de la asignatura a la docencia no presencial durante el mes de marzo se ve la oportunidad de pasar a una fase más abierta de participación durante el bloque de Escultura y Espacio, incentivando la misma con un $10 \%$ de la nota por generación de contenidos. También se valorará positivamente la asistencia e interacción durante las clases en red donde se comentarán los trabajos publicados.

Para la generación de contenido se pide etiquetar el material que se desee subir con@grupo_f52. De este modo se comarte cualquier elemento audiovisual (fotos y vídeos de hasta 15 segundos) para que los usuarios que sigan la cuenta lo vean. Otra de las herramientas disponibles es la del uso del hashtag \#grupo_f52 que mete dentro de una categoría el material específico generado de y para la clase.

A pesar de estas opciones, un porcentaje muy elevado de estudiantes sigue prefiriendo el correo electrónico como medio para compartir información por lo que se habilita también esta opción. El material facilitado será posteriormente valorado y difundido desde la cuenta oficial de la clase.

Debido a la situación de estrés generada en el alumnado y en el profesorado por el estado de alarma a raíz del COVID-19, las fases de Gestión y Difusión de la innovación, en las que se abre la gestión de la cuenta 
a los alumnos y se trabajaba conjuntamente con el resto de profesores de la asisnatura de Escultura II para presentar una galería visual conjunta de la misma se postergan previsiblemente hasta el próximo curso.

Igualmente, la cuenta de Instagram creada constituye un espacio virtual de tránsito donde poder interaccionar como grupo. No solo puede ser utilizada por cada alumno para la presentación y valoración de sus propuestas motivando al resto de compañeros a generar contenido para la asignatura. También combate el aislamiento del estudiante potenciando la pertenencia al grupo, generando inercias que evitan el abandono de la asignatura motivado por las dificultades y deficiencias que presente su situación personal.

Como afirman Miller, Shapiro y Hilding-Hamann (2008), la idea es avanzar hacia espacios de aprendizaje permanentes, interconectados, permeables, modulares y más acordes con las dinámicas laborales de la segunda década del siglo actual, obligando a las instituciones formativas a adoptar esquemas de instrucción más versátiles y experienciales.

\section{Resultados}

Al inicio del curso 2019-2020 hay 52 alumnos matriculados en el Grupo F para Escultura II cifra que se reduce a 50 durante el segundo semestre y, aunque en un principio, la suspensión de las clases presenciales en marzo a causa del Estado de Alarma puede suponer una mayor tasa de abandono, la totalidad del alumnado presenta sus proyectos para ser evaluados y solo el $8 \%$ opta a la prueba final de recuperación, siendo motivo de una subida de nota en el 50\% de los casos.

En la Fig. 6 se recoge la relación de notas por cada una de las 4 UUDD que componen la asignatura de Escultura II. Mientras que, en las tres primeras UUDD esta se mantiene dentro de unas constantes, vemos un aumento considerable en las notas de la primera columna en la UD 4 correspondiente: Escultura y Espacio. El 90\% de los alumnos del grupo de referencia cuenta con una puntuación mayor de 7 frente al $54 \%$ de la UD 1: Escultura y Cuerpo.

Al mismo tiempo, de las autoevaluaciones sugeridas a la entrega de cada memoria se desprende un aumento significativo de la satisfacción del alumno en la realización de este último proyecto, satisfacción que concuerda con la alta participación que se ha hecho presente durante el Estado de Alarma. El porcentaje de asistencia a las clases, correspondientes al horario de la asignatura, a través de la plataforma habilitada por la Universitat Politècnica de València para la docencia no presencial (Teams de Office 365, Microsoft) son de un 52,5\% para el mes de abril y un 50,25\% para el mes de mayo. Dato reseñable si se tiene en cuenta que no era de carácter obligatorio.

En cuanto a la tasa de participación en la cuenta grupo_f52 podemos decir que la incorporación de los alumnos a la cuenta creada es lenta pero progresiva. Tras comenzar con la docencia en red el número de seguidores de la cuenta de Instagram aumenta hasta alcanzar casi el 50\% del grupo de referencia. Mientras que, al finalizar el curso, el número de seguidores del grupo_f52 asciende a 47. Los materiales audiovisuales han sido vistos por el $80 \%$ de los miembros que siguen la cuenta y la participación de estos se traduce en otorgar el like a la foto de sus compañeros. 


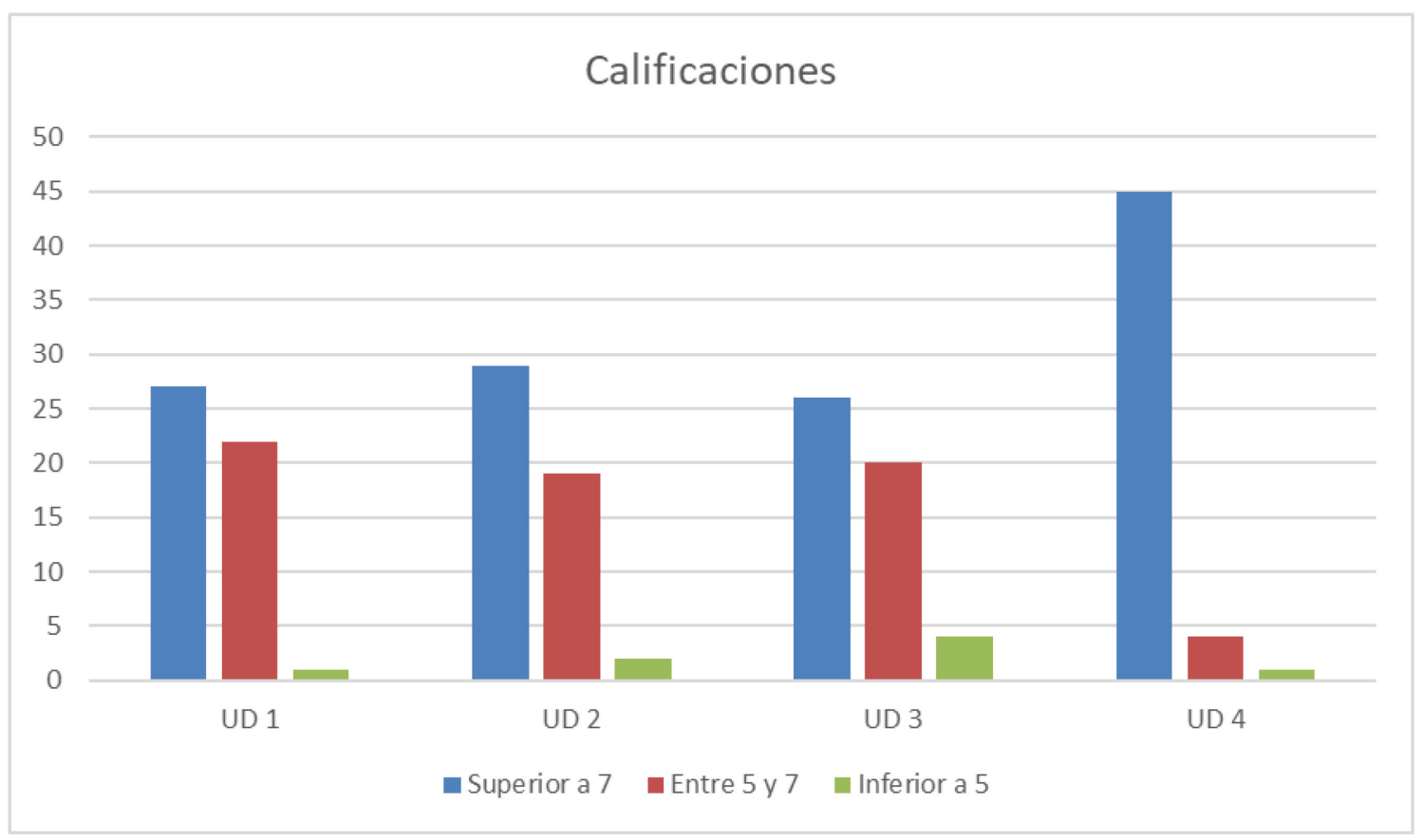

Fig. 7 Notas obtenidas por el grupo de referencia a lo largo del curso 2019-2020 distribuidas por UUDD.

Cabe analizar en posteriores fases si estos datos apuntan a una situación provocada por el confinamiento o si por el contrario son reflejo de un acierto en el uso de las redes sociales para la gestión de la asignatura y la docencia universitaria dentro del ámbito de las artes. Lo que sí podemos afirmar es que el uso de la plataforma Office 365 junto con la participación de la cuenta creada en Instagram ha ayudado a potenciar la identidad de grupo, la colaboración y la generación de contenidos para la asignatura, generando un lugar de encuentro para todos los alumnos del grupo de referencia, favoreciendo una mirada crítica y analítica del hecho artístico apoyada por el análisis colectivo.

También podemos afirmar que el fuerte carácter visual de los nuevos espacios de convivencia, han ayudado al desarrollo de un mayor abanico de posibilidades plásticas para la signatura reconciliándose con un estudiante cuyo perfil no era específicamente escultórico. Este desarrollo se ha visto potenciado a su vez por la situación de confinamiento que ha limitado el acceso a las aulas y talleres por parte del alumnado y le ha obligado a trabajar desde otra mirada.

El uso de procesos creativos asociados a otras asignaturas se ha elevado a un $60 \%$ incluyéndose trabajos que van desde el uso de collage y la intervención fotográfica hasta la instalación pasando por el performance y el vídeo (Fig. 8). Este hecho lejos de suponer una pérdida de la calidad en los trabajos presentados ha supuesto, como queda reflejado en las calificaciones de la Fig. 7, una mejora cualitativa de los procesos creativos y formales emprendidos por los estudiantes. 


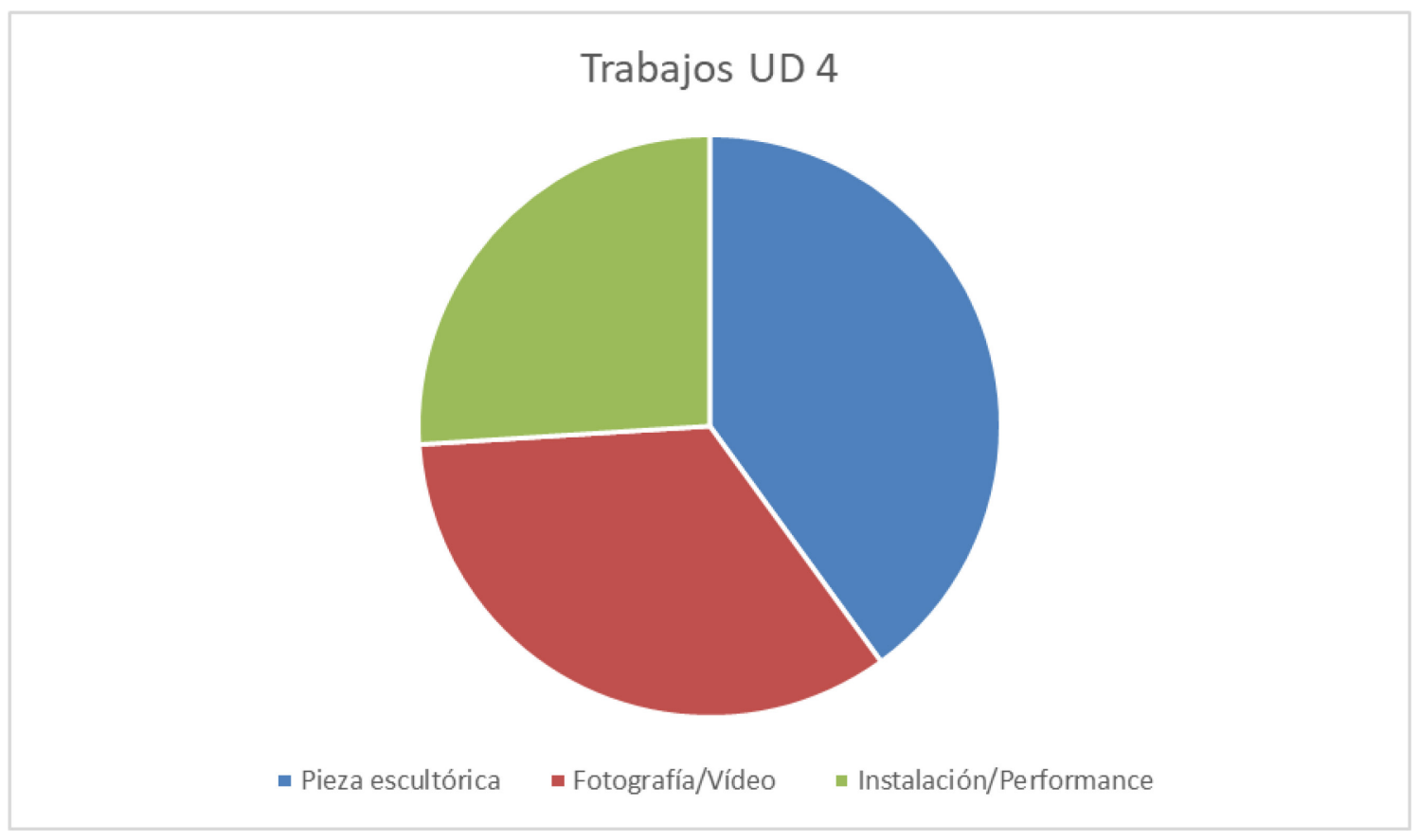

Fig.8. Relación de proyectos presentados para la UD 4: Escultura y Espacio

Es considerable el aumento del valor de la imagen como elemento representativo y narrativo de la obra artística, valor que se pone de manifiesto en el archivo visual del curso generado dentro de la cuenta de Instagram que ha evolucionado paralelamente al grupo. Independientemente a esta evolución podemos afirmar que, al poner en valor la imagen como producto evaluable (por su repercusión en las redes), pudimos ver cómo, en cuestión de pocas sesiones, los estudiantes hicieron un mayor y mejor seguimiento fotográfico de los procesos que realizaban para materializar sus obras independientemente de que estas imágenes fueran a ser subidas o no a la red social.

\section{Conclusiones}

Estamos de acuerdo con las palabras de Villalonga C. y Marta-Lazo, C (2015) cuando afirman que, el aprendizaje móvil cuenta con un ecosistema pedagógico propio sobre el cual es cada vez más necesario reflexionar acerca de su fundamentación teórica como entorno virtual de enseñanza y aprendizaje.

El estado de alarma decretado el 14 de marzo del presente año y la necesidad de adaptar la docencia presencial a la docencia en red apremió a expandir el alcance de esta innovación en busca de nuevos espacios de convivencia. Para ello es necesario como afirman Pérez-Rueda, A., Belanche, D. y Lozano N. (2019) que tanto docentes como estudiantes concreten las normas de uso de cada red social para cada nuevo ecosistema.

La propuesta, ampliamente aceptada por el grupo de estudio, debe someterse nuevamente a revisión al final del curso académico para poder valorar si ha sido de apoyo en el desarrollo de las competencias y prácticas profesionales que pretende la asignatura. Pudiendo cuantificar con mayor precisión su alcance, la participación del alumnado y un cambio en su papel como sujeto pasivo dentro de los sistemas de aprendizaje. 
Hoy en día se ha logrado potenciar el valor de la imagen como elemento representativo y narrativo de la obra artística, generándose una iniciativa que dota al curso de un archivo visual distintivo de las posibilidades plásticas de la asignatura. Al incentivar a los alumnos a que muestren no solo la pieza final sino también los procesos constructivos de sus propuestas, se consigue que el alumno tome conciencia de las diferentes fases del trabajo y se empodere de su propio proyecto.

Es importante establecer estrategias de seguimiento y participación para que el alumnado se involucre de forma activa en la generación de contenido. Para ello es fundamental su familiarización con la aplicación y que se abra la administración de ésta a los estudiantes. Tal y como afirma Pérez-Rueda, A., Belanche, D. y Lozano N. (2019) administrar la cuenta en la red social también contribuye a mejorar los resultados de aprendizaje en competencias transversales tales como el uso de herramientas digitales y el fomento de la creatividad.

Para que el material recogido por la red social sea de interés general es necesario una participación, continua y coordinada tanto del personal técnico, como del docente, así como un estrecho seguimiento de la actividad generada por los estudiantes, lo que supone una carga de trabajo añadida que se debe asumir.

En general, la investigación marca positivamente las bases teóricas de un modelo de trabajo basado en el uso de las TIC, concretamente en la red social Instagram como elemento complementario dentro de las prácticas artísticas para la docencia, respondiendo a la necesidad de la asignatura de contribuir al desarrollo del pensamiento crítico del alumno, dotándole de un bagaje técnico y artístico que le permita relacionar los diferentes acontecimientos contemporáneos generando estrategias y discursos que contribuyan al desarrollo de propuestas creativas a nivel formal y conceptual desde una realidad no presencial.

\section{Referencias}

APARICI, R. (Coord.) (2010). Educomunicación más allá del 2.0. Barcelona: Gedisa. $<\underline{\text { https://bit.ly/3hOrPaH }>}$ [Consulta: 28-7-2020].

BELANCHEA, D. LOZANO, N. y PÉREZ RUEDA, A. (2019). "Instagram como herramienta de aprendizaje en el a

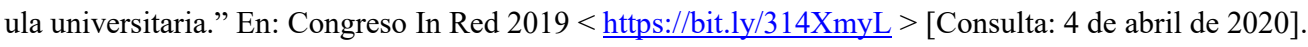

DE LA TORRE ESPEJO, A. (2009). "Nuevos perfiles en el alumnado: la creatividad en nativos digitales competentes y expertos rutinarios". En Revista de Universidad y Sociedad de conocimiento [monográfico en línea]. Revista de Universidad y Sociedad del Conocimiento (RUSC). Vol. 6, n. ${ }^{\circ}$ 1; 9. UOC. (2009) < https://bit.ly/2CMj9De $>$ [Consulta: $28-7-2020]$.

FANDOS GARRIDO, M. (2003). "Formación basada en las Tecnologías de la Información y Comunicación: Análisis didáctico del proceso de enseñanza aprendizaje.” Tesis Doctoral. Tarragona: Universitat Rov ira y Virgili. $<$ https://bit.ly/3hDQJtz $>$ [Consulta: 4 de abril de 2020].

GONZÁLEZ MARTÍNEZ, J., LLEIXÀ FORTUÑO, M., ESPUNY VIDAL, C. (2016). "Las redes sociales y la educación superior: las actitudes de los estudiantes universitarios hacia el uso educativo de las redes sociales, de nuevo a examen”. En Education in The Knowledge Society $(E K S)$. Vol. 17, n. ${ }^{\circ} 2(2016)<\underline{\text { https://bit.ly } / 3 \mathrm{fbLGz0}}>$ [Consulta: 28-7-2020].

HISCOX (2019). Hiscox Online Art Trade Report $2019<$ https://bit.ly/39DLuri > [Consulta: 4 de abril de 2020].

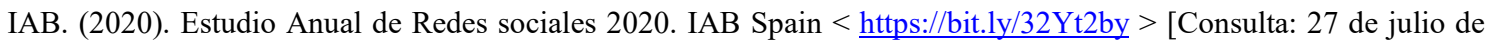
2020].

IMBERNÓN, F., SILVA, P., \& GUZMÁN, C. (2011). Competencias en los procesos de enseñanza-aprendizaje virtual y semipresencial. Comunicar, 36, 107-114. $<$ https://bit.ly/3hDo9sm $>$ [Consulta: 28-7-2020]. 
INTEF (2011). "First UNESCO Mobile Learning Week. Resumen Informe de la Primera Semana del Aprendizaje Móvil”. UNESCO. < https://bit.ly/3g4VnAC $>$ [Consulta: 4 de abril de 2020].

MARTA-LAZO, C. (2018). "Las TRIC (Tecnologías de la Relación, la Información y la Comunicación) al servicio de la educomunicación para la salud”. LAAB < https://bit.ly/39wycMX $>$ [Consulta: 4 de abril de 2020].

MARTÍN-MORENO, Q. (2004). Aprendizaje colaborativo y redes de conocimiento. Actas de las IX Jornadas Andaluzas de Organización y Dirección de Instituciones Educativas, Granada. Grupo Editorial Universitario, 55-70.< https://bit.ly/3g6slk0 $>$ [Consulta: 28-7-2020].

MILLER, R., SHAPIRO, H., HILDING-HAMANN, K. E., (2008). "School's Over: Learning Spaces in Europe in 2020 An Imagining Exercise on the Future of Learning". En JRC Scientific and Technical Reports. European Commission IPTS < https://bit.ly/3f9kW2f $>$ [Consulta: 28-7-2020].

MORENO MORENO, M. P. (2018). "Uso docente de la red social "Instagram" en la asignatura de Proyec-tos 1". En: JIDA'18 < https://bit.ly/2ByhRuK $>$ [Consulta: 4 de abril de 2020].

RAMOS, A.I. HERRERA J.A. y RAMÍREZ M.S. (2010).” Desarrollo de habilidades cognitivas con aprendizaje móvil: un estudio de casos". Comunicar, n. ${ }^{\circ}$ 34, v. XVII, 2010, Revista Científica de Educomunicación; ISSN: 1134 3478; páginas 201209 < https://bit.ly/3jTDAyK >. [Consulta: 4 de abril de 2020].

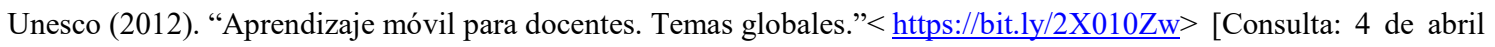
de 2020].

VILLALONGA, C. y MARTA-LAZO, C. (2015). “Modelo de integración educomunicativa de 'Apps' móviles para la enseñanza y aprendizaje.” Píxel Bit. Revista de Medios y Educación. N. ${ }^{\circ} 46$. Enero 2015. ISSN: 1133 8482.e ISSN: 2171 7966. doi: http://dx.doi.org/10.12795/pixelbit.2015.i46.09 < https://bit.ly/3jIsM $\underline{\mathrm{mJ}}>$ [Consulta: 4 de abril de 2020].

VIVES, N. (2012). “Mobile Learning, una oportunidad para el cambio”. En Fundación Telefónica (diciembre, 2012).

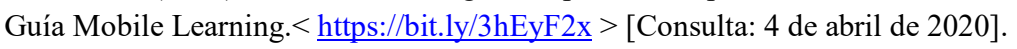

